\title{
Vaginal candidiasis in Konya area: Etiology, risk factors, virulence patterns, and antifungal susceptibility
}

\author{
Semih Tokak ${ }^{1,2}$, İbrahim Halil Kılıç ${ }^{1 *}$, Jule Eriç Horasanlı ${ }^{3}$, Elif Gülbahçe Mutlu ${ }^{4}$, \\ Fatma Esenkaya Taşbent ${ }^{5}$, Işık Didem Karagöz ${ }^{1}$ \\ 1.Department of Biology, Faculty of Science and Literature, Gaziantep University, Turkey \\ 2. Department of Medical Microbiology, Faculty of Medicine, KTO Karatay University, Turkey \\ 3. Department of Obstetrics and Gynecology, Faculty of Medicine, Necmettin Erbakan University, \\ Turkey \\ 4. Department of Medical Biology, Faculty of Medicine, KTO Karatay University, Turkey
}

5. Department of Medical Microbiology, Faculty of Medicine, Necmettin Erbakan University, Turkey

\begin{abstract}
Vulvovaginal candidiasis (VVC), a common genital tract infection, is known to affect millions of women worldwide. In this study, it was aimed to determine the prevalence, virulence, possible risk factors and antifungal susceptibility model of Candida species. Vaginal swab samples were taken from patients aged 18 years and older who presented to the gynecology outpatient clinic with signs and symptoms suggestive of vulvovaginitis. Demographic data were recorded using a questionnaire. Standard microbiological methods were used for the identification of the isolates. Broth microdilution method was used to determine the antifungal susceptibility of Candida isolates. Virulence factors of Candida strains were determined by performing proteinase, phospholipase, hemolytic and biofilm activity tests. Sequencing of the isolates identified as Candida were performed using ITS 1-4 primers. Vaginal discharge (OR: 3.365; 95\% CI: 1.595-7.101), burning complaint (OR: 9.098; 95\% CI: 2.284-36.232) and history of allergy (OR: 3.396; 95\% CI: 0.968) were risk factors. The results showed that the most common isolated strain was Candida albicans (57\%). It was found that the prevalence of C. glabrata remained at 26\%, 44 of the C. albicans isolates presented proteinase, 35 had phospholipase, 47 had biofilm, and 47 had hemolytic activity. In this study, susceptible dose-dependent and resistant rates of all Candida strains were found for fluconazole as $9 \%$ and $16 \%$, respectively. Host and organism-related factors should be considered in the clinical treatment of VVC, and continuous monitoring of changes in the prevalence of Candida species and susceptibility rates is required for effective antifungal therapy.
\end{abstract}

Keywords: Candida vaginitis, genotypic identification, virulence factors, risk factors, antifungal susceptibility Received: $8^{\text {th }}$ October, 2020; Accepted: 14 ${ }^{\text {th }}$ January 2021; Published: $16^{\text {th }}$ February 2021

\footnotetext{
* Corresponding author: İbrahim Halil Kılıç, Department of Biology, Faculty of Science and Literature, Gaziantep
} University, Turkey. E-mail: kilic@gantep.edu.tr 


\section{Introduction}

Vaginitis infections are one of the opportunistic infections in women and may present themselves with obvious symptoms or asymptomatic during routine examinations. Normal vaginal flora may vary depending on the $\mathrm{pH}$ of the environment, age, hormonal status, sexual activity, method of contraception, drugs used, antibiotics, and surgical interventions (1). Candida species are distributed widely both in living organisms and in a wide variety of environments such as hospitals $(2,3)$. These species are members of the human microbiome. They are abundant in the genital area, urine, skin, oral cavity, scalp, nails, and mucosal surfaces of the respiratory and digestive tracts (2). In most women, they can reach the lower genital tract from the lower perianal region without signs of infection (4). Pathogenicity of these species is thought to be caused by some virulence factors such as protection from host defense mechanisms with filamentous forms, adhesion to host tissue, biofilm-forming capacity, production of phospholipases, which are tissue-destructive hydrolytic enzymes, lipase and hemolysin (5). Aspartyl proteinases and phospholipases, which are among these hydrolytic enzymes, are important enzymes secreted by Candida species in both the yeast phase and the hyphae phase and have been reported to induce tissue invasion (6). The most important factors causing Candida infections are changes in the host vaginal/vulvar environment. The infection that occurs in this case is called vulvovaginal candidiasis (VVC). This disease is particularly caused by Candida species in the absence of other bacterial agents. Considering that the most common cause of vaginal infections is vaginosis, VVC can be considered as the second most important cause of these infections (7). Vulvar or vaginal erythema, hyperemia, itching, pain, burning are the most common clinical signs of VVC. It is estimated that $10-15 \%$ of patients colonized with Candida are asymptomatic. Si- milarly, it is estimated that $70-75 \%$ of women colonized with Candida will experience VVC attacks during their lifetime, $50 \%$ of women who were initially infected will experience a second VVC, and $5-10 \%$ of all women will develop recurrent VVC (8). The factors that lead to $\mathrm{VVC}$ are generally increased sexual activity, high amount of estrogen or oral contraceptives, pregnancy, antibiotic use, diabetes, corticosteroid use, hormone replacement therapy, chemotherapy or vaginal douching (9). The most common Candida species causing this disease are C. albicans, C. glabrata, C. parapsilosis, C. krusei and C. tropicalis. Generally, there is only one type in etiology, but two or more types were detected in $1-10 \%$ of women with VVC. Coexistence of C. albicans and C. glabrata is more common when there is more than one Candida agent (10). Although significant therapeutic advances have been made in the treatment of this disease, the mechanisms that trigger VVC have unfortunately not yet been fully discovered. Therefore, it is considered appropriate to review the epidemiology of this disease, the specific risk factors and what is known about the virulence factors of Candida species. In this study, we aimed to determine the prevalence, virulence, possible risk factors and antifungal susceptibility model of Candida species.

\section{Methods}

\section{Research population}

This study was prospectively conducted in a tertiary university hospital over a 2-year period from April 2018 to April 2020.

The study protocol had the approval of the Ethics Committee of KTO Karatay University Medical Faculty (no. 41901325-050.99/date 21.02.2019). In the study, vaginal swab samples were taken from patients aged 18 years and older who presented to the gynecology outpatient clinic with signs and symptoms suggestive of vulvovagini- 
tis. Demographic data were recorded using a questionnaire. Patients with yeast growth in culture and those with normal vaginal microflora were accepted as the case and control groups, respectively. The following individuals were not included in the study: pregnant women, those who did not want to participate in the study, those with a known history of gynecological cancer, patients with vaginal complaints who had been treated in the previous month, those who had had sexual intercourse in the last three days, girls with a hymen, those who had vaginal bleeding during the study and those who had menstrual period. Written informed consent was obtained from the patients included in the study, explaining the aim of the study. In line with the literature information obtained, the patients were asked 26 questions about demographic data, chronic disease history, gynecological history, sexual and menstrual behavior history, main complaints and other problems in a five-part form, which was prepared to identify specific risk factors.

\section{Sampling}

Two swab samples were taken from the posterior fornix and the lateral wall of the vagina with a sterile swab during the gynecological examination performed with a speculum for sampling. One of the swab samples taken from the patients was placed in a tube modified Stuart's medium and the other was placed in a $0.5 \mathrm{ml}$ sterile saline tube. Before, each sample of vaginal swab was done by gram staining and examined microscopically. Direct examination was positive if it showed regular blastopores, as well as pseudopyphae and blastopores. Afterwards, the other swab was inoculated on Sabouraud Dextrose Agar (SDA, Merck, Germany) and then plates incubated at $37{ }^{\circ} \mathrm{C}$ for $48 \mathrm{~h}$. After the incubation period, germ tube test and gram staining (Gram-positive budding cells with round or oval morphology were considered Candida positive), which are phenotypic methods, were applied to the yeast-looking colonies grown on the medium to determine the microorganisms that grew. Germ tube test was used to differentiate C. albicans, C. dubliniensis and C. africana from other Candida species (11). Human serum was used to reproduce Candida species. It was observed that the cells incubated at $37^{\circ} \mathrm{C}$ for 3 hours formed germ tubes detectable with $\mathrm{KOH}$ films.

In addition, in order to identificate the strains including chlamydoconidia formation, urease activity, growth at various temperatures; and carbohydrate assimilation patterns assays were performed. In addition, rapid identification test kits such as API 20C AUX system (Biomérieux, France) were used to identify the isolates.

In our study, the following criteria were used in the diagnosis of VVC, and the patient with at least one of them was diagnosed with VVC. These criteria are: appearance of budding yeast, pseudohyphae or hyphae in microscopic examination of wet-mount and Gram stained preparations; the presence of a large number of yeast in the culture $\left(>10^{3} \mathrm{CFU} / \mathrm{ml}\right.$ suspension $)$ and no yeast cells in microscopic examination, and the presence of symptoms and signs (vaginal discharge, vulvar and vaginal erthtema and pruritus, burning, inguinal pain) related to VVC in the patient were considered to be positive. A small number of yeast $\left(<10^{3} \mathrm{CFU} / \mathrm{ml}\right.$ suspension) in the culture and no yeast in the microscopic examination were considered to be colonization and the patient was VVC negative (12).

\section{Molecular diagnosis}

DNA isolation from samples was performed with the "High Pure PCR Template Preparation Kit" (Roche Diagnostic, USA) according to the manufacturer's recommendations. Polymerase chain reaction (PCR) was performed by using ITS1 (forward) 5'-TCCGTAGGTGAACCTGCGG-3 'and ITS4 (reverse) 5'-TCCTCCGCTTATTGATATGC-3' (Sentebiolab, Turkey) primers. Based on a previously defined method, PCR reaction was carried out in 35 cycles following a 2 minute 
initial denaturation at $95^{\circ} \mathrm{C}$ in a thermal cycler device (BioRad, Italy) in 30 seconds, 2 minutes at $58{ }^{\circ} \mathrm{C}$, and 1 minute at $72{ }^{\circ} \mathrm{C}$, and lastly $5 \mathrm{mi}-$ nutes at $72{ }^{\circ} \mathrm{C}$ as the final cycle. Amplification products were run on a $1.5 \%$ agarose gel containing $0.5 \mu \mathrm{g} / \mathrm{ml}$ ethidium bromide and visualized under UV light. Sequencing of PCR amplicons was performed by Sanger (capillary electrophoresis) sequencing. All amplicons were purified using the ExoSap-IT (Applied Biosystems, California, USA). The DNA fragments were sequenced using an automated DNA sequencer (ABI PRISM 377, Taiwan) with a BigDye Terminator kit (Applied Biosystems, Taiwan). Amplicons were sequenced using ITS1 and ITS4 primer.

Sequence analysis data were evaluated using the "National Center for Biotechnology Information (Bethesda, USA)" BLAST system (http://www. ncbi.nlm.nih.gov/BLAST/) and strains were identified at species level. The phylogenetic tree was created with MEGA 7.0 software (Fig. 1 ). The confidence levels of the monophyletic group were determined using bootstrap analysis (1,000 copies).

\section{Virulence factors}

Acid proteinase activity was investigated on agar plates containing bovine serum albumin (BSA) as defined by Staib (13). BSA agar plates were prepared by adding $1 \% \mathrm{BSA}, 2 \%$ agar, $2 \%$ glucose, $0.05 \% \mathrm{MgSO}_{4}$ and $0.01 \% \mathrm{KH}_{2} \mathrm{PO}_{4}$. $10 \mu 1$ of the suspension prepared in cultures was inoculated into plates and allowed to incubate at $37^{\circ} \mathrm{C}$. Acid proteinase activity was assessed by halo formation around the colony at the end of the third day (14). Phospholipase activity was studied on egg yolk-containing agar plates as described by Price et al. (15). In the preparation of this medium, SDA medium, $1 \mathrm{M} \mathrm{NaCl}, 0.005$ $\mathrm{M} \mathrm{CaCl}_{2}$ and $8 \%$ egg yolk were used. The egg yolk was centrifuged at $500 \mathrm{xg}$ for $15 \mathrm{~min}$ before adding to the medium. The supernatant was taken into a sterile tube and added to the medium when the temperature reached $50{ }^{\circ} \mathrm{C}$ after autoclaving. The prepared medium was then poured into the plates. The suspension prepared from the yeast colony was inoculated into $10 \mu \mathrm{l}$ of medium and incubated at $37{ }^{\circ} \mathrm{C}$. On the third day of incubation, white zone formation around the colony was evaluated in favor of phospholipase activity (16).

To determine the hemolytic activity of the isolated samples, the method described by Luo et al. (17) was used. After the isolated samples were incubated at $37^{\circ} \mathrm{C}$ for $24 \mathrm{~h}$, the suspension inoculated in SDA was prepared in sterile saline at a rate of $1 \times 10^{8}$ cells $/ \mathrm{ml}$. $10 \mu \mathrm{l}$ of this suspension was taken and inoculated into SDA containing $7 \%$ sheep blood and 3\% glucose. Plates were incubated in the presence of $5 \% \mathrm{CO}_{2}$ at $37{ }^{\circ} \mathrm{C}$ for $48 \mathrm{~h}$. The distinct transparent zone formed around the inoculum area was accepted as positive hemolytic activity.

The modified tube adherence method was used to investigate the biofilm production potential. After 24-48 h incubation in SDA, a loopful colony was picked, inoculated into tubes containing Sabouraud broth (SB) with a final glucose concentration of $8 \%$ and incubated for $48 \mathrm{~h}$ at $37^{\circ} \mathrm{C}$. After incubation was completed, the contents of the tubes were emptied, washed twice with distilled water, and then stained with $1 \%$ safranine. After the tubes were dried in air, the presence of a colored film layer on the inner wall was evaluated as biofilm positive. Biofilm positivity was evaluated as weak positive $(+)$, medium positive $(++)$ and strongly positive $(+++)$, according to the thickness of the layer formed (18).

\section{Antifungal susceptibility test}

For susceptibility experiments of the isolated sample, caspofungin (Sigma, China), amphotericin B (Sigma, Israel), fluconazole (Sigma, USA), ketoconazole (Sigma, China), voriconazole (Sigma, USA) and posaconazole (Sigma, USA) were 
used as antifungals. The CLSI-recommended cut-off values in M27-S3 and M27-S4 were used to determine the antifungal susceptibility of the isolates $(19,20)$. In the absence of sufficient data to develop species-specific clinical limit values, the "epidemiological cut-off value (ECV)" was used to identify isolates that were less responsive to treatment. Epidemiological cut-off values were used to differentiate wild (not exposed to antifungal or acquired resistance mechanisms) and non-wild types (mutational or acquired resistant isolates) (21).

In U bottom shaped 96-well microplates, using two-fold serial dilutions, solutions varying in ranges of $0.015-8,0.0313-16,0.125-64,0.0313$ 16 , and $0.0313-16 \mu \mathrm{g} / \mathrm{ml}$ for caspofungin, amphotericin $\mathrm{B}$, fluconazole, voriconazole and for posaconazole were prepared, respectively. $C$. krusei ATCC 6258 and C. parapsilosis ATCC 22019 strains were used as controls. At the end of $24 \mathrm{~h}$ of incubation at $37^{\circ} \mathrm{C}$, the microplates were evaluated with the naked eye and the minimum inhibitory concentration (MIC) values were determined. The lowest antifungal concentration in the well where the growth showed a $50 \%$ reduction compared to the growth in the control well without antifungal was considered as the MIC value.

\section{Statistical analysis}

IBM SPSS v.25 was used for data analysis. Chi-square test, univariate analysis and Fisher's exact test were used to obtain quantitative statistical data. In addition, the relationship between dependent and independent variables was documented through bivariate and multivariate logistic regressions. Using these analyses, odds ratios (OR) and 95\% confidence interval (CI) associated with risk factors were calculated. ' $p$ ' values less than 0.005 were considered statistically significant.

\section{Results}

200 patients with signs and symptoms of vaginitis between April 2018 and April 2020 were included in the study. 100 patients with Candida growth in vaginal swab culture were included in the case group, and 100 patients with no growth in the culture were included in the control group. The ages of the patients included in the study ranged from 18 to 59, with a mean age of $33.7 \pm$ $8.51 .180(90 \%)$ of the participants were married. Basic demographic and clinical characteristics of the women in the case and control groups are presented in Table 1 and 2. When the basic characteristics of the women included in the study were examined, no significant difference was found between the case and the control groups $(p>0.05)$. When the basic clinical features were examined, a significant difference was found between the case and the control groups in terms of allergy history, discharge, itching, burning, and groin pain $(p<0.05)$ (Table 2$)$. According to multivariate analysis results, risk factors for vaginitis were discharge (OR: 3.365; 95\% CI: 1.595-7.101), burning complaint (OR: 9.098; 95\% CI: 2.284-36.232), and history of allergy (OR: 3.396, 95\% CI: 0.968-11.910) (Table 3).

In Gram stained smears, budding yeast cells (blastoconidia) and/or pseudohyphae showing regular points of constriction identified as Candida spp.

As a result of bidirectional DNA sequence analysis of the ITS1 and ITS4 regions of the isolates identified as Candida by phenotypic tests (germ tube test and gram staining), it was determined that they consisted of five different species. Accordingly, the most dominant species were C. albicans (57\%), C. glabrata (26\%), C. kefyr (12\%), C. krusei (3\%) and C. dubliniensis (2\%). The evolutionary relationship between strains was evaluated by using the Neighbor-Joining method and the MEGA program. Phylogenetic analysis of the strains is shown in Figure 1. 
Table 1. Basic demographic characteristics of the women included in the study.

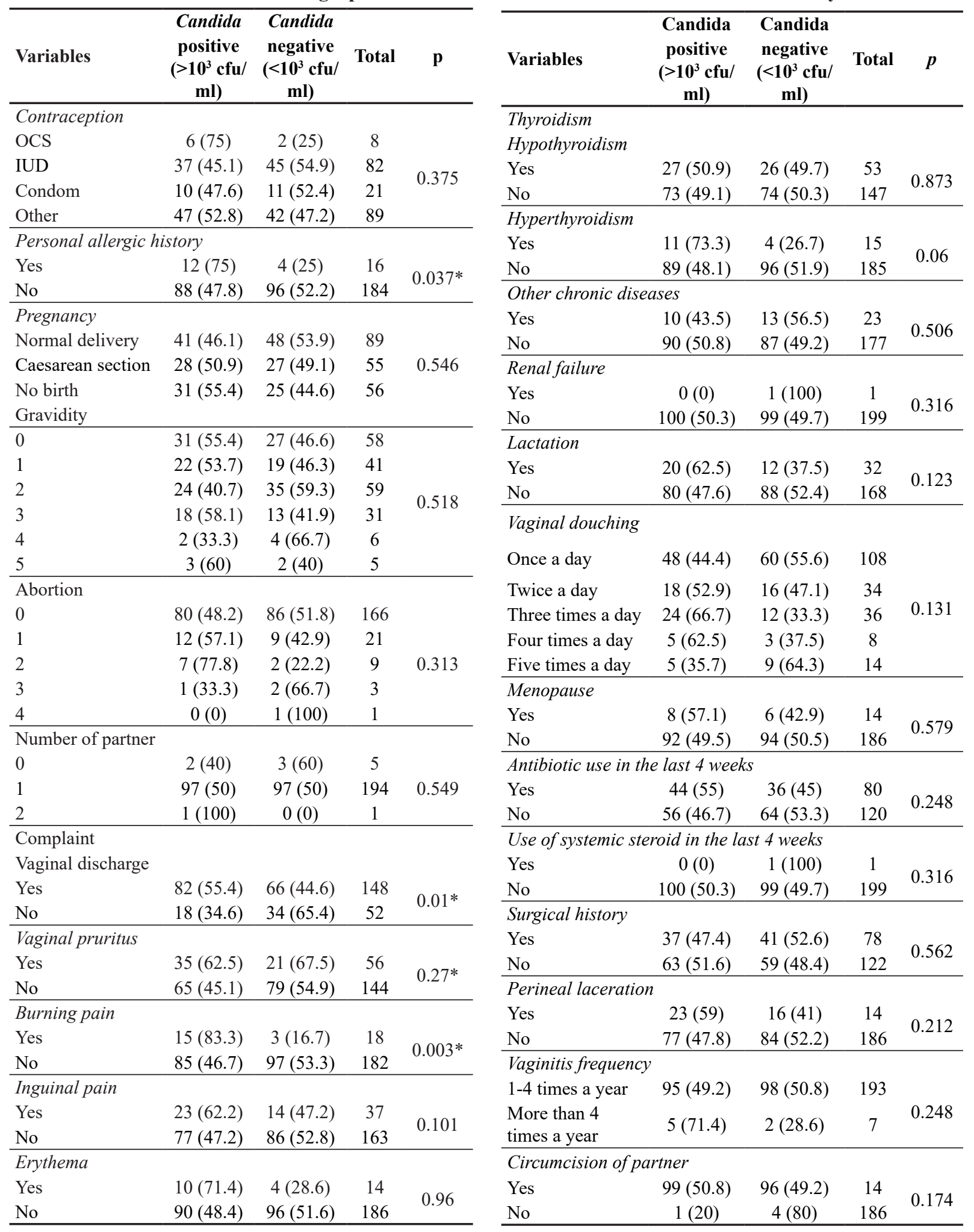


Table 2. Basic clinical characteristics of the women included in the study.

\begin{tabular}{|c|c|c|c|c|}
\hline Variables & $\begin{array}{c}\text { Candida } \\
\text { positive } \\
\left(>10^{3} \mathrm{cfu} /\right. \\
\mathrm{ml})\end{array}$ & $\begin{array}{c}\text { Candida } \\
\text { negative } \\
\left(<10^{3} \mathrm{cfu} /\right. \\
\mathrm{ml})\end{array}$ & Total & $p$ \\
\hline \multicolumn{5}{|l|}{ Age } \\
\hline $18-29$ & $44(51.2)$ & $42(48.8)$ & 86 & \multirow{4}{*}{0.214} \\
\hline $30-39$ & $41(55.4)$ & $33(44.6)$ & 84 & \\
\hline $40-49$ & $9(32.1)$ & $19(67.9)$ & 28 & \\
\hline $50>$ & $6(50)$ & $6(50)$ & 12 & \\
\hline \multicolumn{5}{|l|}{ Marital status } \\
\hline Married & 88 (48.9) & $92(51.1)$ & 180 & \multirow{3}{*}{0.315} \\
\hline Single & $10(55.6)$ & $8(44.4)$ & 18 & \\
\hline $\begin{array}{l}\text { Widowed-Di- } \\
\text { vorced }\end{array}$ & $2(100)$ & $0(0)$ & 2 & \\
\hline \multicolumn{5}{|l|}{ Education status } \\
\hline Primary school & $14(56)$ & $11(44)$ & 25 & \multirow{4}{*}{0.509} \\
\hline High school & $31(43.7)$ & $40(56.3)$ & 71 & \\
\hline University & $54(53.5)$ & $47(46.5)$ & 101 & \\
\hline Graduate & $1(33.3)$ & $2(66.7)$ & 3 & \\
\hline \multicolumn{5}{|l|}{ Occupation } \\
\hline House wife & $55(47.4)$ & $61(52.6)$ & 116 & \multirow{3}{*}{0.470} \\
\hline Employee & $42(52.5)$ & $38(47.5)$ & 80 & \\
\hline Student & $3(75)$ & $1(25)$ & 4 & \\
\hline \multicolumn{5}{|l|}{ Tobacco use } \\
\hline Yes & $15(53.6)$ & $13(46.4)$ & 28 & \multirow{2}{*}{0.684} \\
\hline No & $85(49.4)$ & $87(50.6)$ & 172 & \\
\hline
\end{tabular}

\begin{tabular}{|c|c|c|c|c|}
\hline Variables & $\begin{array}{c}\text { Candida } \\
\text { positive } \\
\left(>10^{3} \mathrm{cfu} /\right. \\
\mathrm{ml})\end{array}$ & $\begin{array}{c}\text { Candida } \\
\text { negative } \\
\left(<10^{3} \mathrm{cfu} /\right. \\
\mathrm{ml})\end{array}$ & Total & $p$ \\
\hline \multicolumn{5}{|l|}{ Alcohol use } \\
\hline Yes & $2(50)$ & $2(50)$ & 4 & \multirow{2}{*}{0.999} \\
\hline No & $98(50)$ & $98(50)$ & 196 & \\
\hline \multicolumn{5}{|c|}{ Common uses } \\
\hline \multicolumn{5}{|l|}{ Toilets } \\
\hline Yes & $38(50.7)$ & $37(49.3)$ & 75 & \multirow{2}{*}{0.884} \\
\hline No & $62(49.6)$ & $63(50.4)$ & 125 & \\
\hline \multicolumn{5}{|c|}{ Epilation center } \\
\hline Yes & $15(53.6)$ & $13(46.4)$ & 28 & \multirow{2}{*}{0.684} \\
\hline No & $85(49.4)$ & $87(50.6)$ & 172 & \\
\hline \multicolumn{5}{|l|}{ Sauna } \\
\hline Yes & $2(20)$ & $8(80)$ & 10 & \multirow{2}{*}{0.52} \\
\hline No & $98(51.6)$ & $92(48.4)$ & 190 & \\
\hline \multicolumn{5}{|c|}{ Turkish bath } \\
\hline Yes & $58(55.8)$ & $46(44.2)$ & 104 & \multirow{2}{*}{0.89} \\
\hline No & $42(43.8)$ & $54(56.2)$ & 96 & \\
\hline \multicolumn{5}{|c|}{ Pad and underwear usage } \\
\hline $\begin{array}{l}\text { Menstrual } \\
\text { pad }\end{array}$ & $16(38.1)$ & $26(61.9)$ & 42 & \multirow{3}{*}{0.110} \\
\hline Daily pad & $33(47.8)$ & $36(52.2)$ & 69 & \\
\hline $\begin{array}{l}\text { Cotton un- } \\
\text { derwear }\end{array}$ & $51(57.3)$ & $38(42.7)$ & 89 & \\
\hline
\end{tabular}

Table 3. Analysis of predictive factors for Candida vaginitis using multivariate logistic analyses.

\begin{tabular}{lccc}
\hline Predictores & \multicolumn{3}{c}{ Multivariate analysis } \\
\hline Vaginal discharge & 3.365 & $\boldsymbol{p}$ & $\mathbf{\% 9 5}$ CI \\
\hline Vaginal pruritus & 1.469 & 0.001 & $1.595-7.101$ \\
\hline Burning pain & 9.098 & 0.27 & $0.753-2.866$ \\
\hline Personal allergic history & 3.396 & 0.05 & $2.284-36.232$ \\
\hline
\end{tabular}

When virulence factors of the detected isolates were examined, proteinase activity in 52, phospholipase activity in 38 , biofilm activity in 79 and hemolytic activity in 95 of Candida species were detected. It was found that none of the C. glabrata, C. kefyr and C. krusei strains produced phospholipase. Proteinase, phospholipase, biofilm forming, and hemolytic activity properties of all isolates are shown in Table 4.
Amphotericin and caspofungin showed good activity against five Candida species. Resistance to fluconazole was detected in $15.8 \%$ of $C$. albicans and $26.9 \%$ of $C$. glabrata isolates. Resistance to voriconazole was detected in $7.1 \%$ of C. albicans isolates. Caspofungin resistance was detected in $5.3 \%$ of $C$. albicans and $7.7 \%$ of $C$. glabrata isolates. 37 of the C. albicans, 22 of the C. glabrata, 6 of the C. kefyr and 3 of the $C$. 

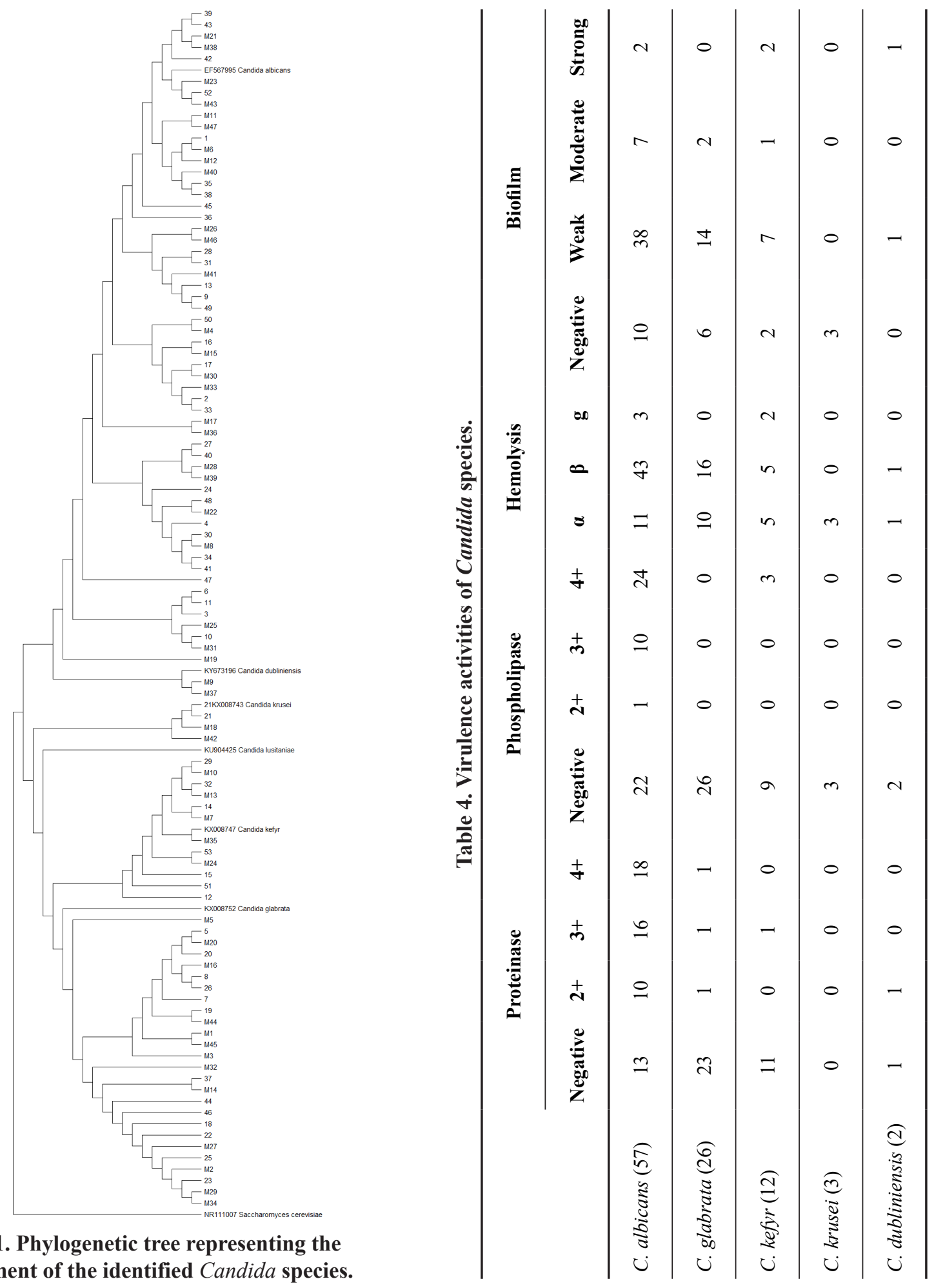

Fig. 1. Phylogenetic tree representing the placement of the identified Candida species. 
krusei isolates were evaluated as wild strains according to the epidemiological cut-off values of ketoconazole. 18 strains of C. albicans, 2 strains of C. glabrata, 6 strains of $C$. kefyr and 2 strains of $C$. krusei were evaluated as wild strains according to the epidemiological cut-off values of posaconazole. C. dubliniensis strains were evaluated as non-wild strains according to the epidemiological cut-off values of amphotericin, ketoconazole, and fluconazole (Table 5).

Table 5. Antifungal susceptibility rates of Candida species.

\begin{tabular}{|c|c|c|c|c|c|c|c|c|c|}
\hline \multirow{4}{*}{$\begin{array}{l}\text { Activities of anti- } \\
\text { fungal agents by } \\
\text { species }\end{array}$} & \multirow{4}{*}{ MIC Range } & \multirow{4}{*}{$\mathrm{MIC}_{50}$} & \multirow{4}{*}{$\mathrm{MIC}_{90}$} & \multirow{4}{*}{$\begin{array}{c}\text { Sensitive } \\
\text { n (\%) }\end{array}$} & \multirow{4}{*}{$\begin{array}{c}\begin{array}{c}\text { Sensitive } \\
\text { Dose }\end{array} \\
\text { Dependent } \\
\text { n (\%) }\end{array}$} & \multirow{4}{*}{$\begin{array}{c}\text { Interme- } \\
\text { diate } \\
\text { n }(\%)\end{array}$} & \multirow{4}{*}{$\begin{array}{c}\text { Resis- } \\
\text { tant } \\
\text { n }(\%)\end{array}$} & \multirow{4}{*}{$\begin{array}{c}\text { Wild } \\
\text { Type } \\
\text { n (\%) }\end{array}$} & \multirow{4}{*}{$\begin{array}{c}\text { Non-Wild } \\
\text { Type } \\
\text { n (\%) }\end{array}$} \\
\hline & & & & & & & & & \\
\hline & & & & & & & & & \\
\hline & & & & & & & & & \\
\hline \multicolumn{10}{|l|}{ C. albicans $(n=57)$} \\
\hline Amphotericin B & $0.03-1$ & 0.25 & 1 & $57(100)$ & - & - & 0 & - & - \\
\hline Ketoconazole & $0.03-4$ & 0.5 & 4 & - & - & - & - & 37 & 20 \\
\hline Fluconazole & $0.125-64$ & 2 & 16 & $39(68.4)$ & $9(15.8)$ & - & $9(15,8)$ & - & - \\
\hline Posaconazole & $0.03-2$ & 0.5 & 2 & - & - & - & - & 39 & 18 \\
\hline Voriconazole & $0.03-1$ & 0.125 & 0.5 & $43(75.4)$ & - & $10(17.5)$ & $4(7,1)$ & - & - \\
\hline Caspofungin & $0.015-4$ & 0.015 & 0.015 & $54(94.7)$ & - & - & $3(5,3)$ & - & - \\
\hline \multicolumn{10}{|l|}{ C. glabrata $(n=26)$} \\
\hline Amphotericin B & $0.03-1$ & 0.25 & 0.5 & $26(100)$ & - & - & 0 & - & - \\
\hline Ketoconazole & $0.03-2$ & 0.5 & 1 & - & - & - & - & 22 & 4 \\
\hline Fluconazole & $0.25-64$ & 8 & 32 & $19(73.1)$ & - & - & $7(26.9)$ & - & - \\
\hline Posaconazole & $0.03-2$ & 0.5 & 2 & - & - & - & - & 24 & 2 \\
\hline Voriconazole & $0.03-1$ & 0.125 & 0.5 & - & - & - & - & 22 & 4 \\
\hline Caspofungin & $0.015-4$ & 0.015 & 0.015 & $24(92.3)$ & - & - & $2(7.7)$ & - & - \\
\hline \multicolumn{10}{|l|}{ C. kefyr $(n=12)$} \\
\hline Amphotericin B & $0.25-1$ & 0.25 & 0.5 & $12(100)$ & - & - & 0 & - & - \\
\hline Ketoconazole & $0.03-4$ & 0.5 & 2 & - & - & - & - & 2 & 10 \\
\hline Fluconazole & $0.25-16$ & 2 & 16 & - & - & - & - & 8 & 8 \\
\hline Posaconazole & $0.03-2$ & 0.25 & 1 & - & - & - & - & 6 & 6 \\
\hline Voriconazole & $0.03-1$ & 0.125 & 1 & - & - & - & - & 9 & 3 \\
\hline Caspofungin & $0.015-4$ & 0.015 & 0.015 & - & - & - & - & 10 & 2 \\
\hline \multicolumn{10}{|l|}{ C. krusei $(n=3)$} \\
\hline Amphotericin B & $0.125-0.25$ & 0.125 & 0.125 & $3(100)$ & - & - & 0 & - & - \\
\hline Ketoconazole & $0.5-2$ & 0.5 & 0.5 & - & - & - & - & 3 & 0 \\
\hline Fluconazole & $0.25-4$ & 0.25 & 0.5 & - & - & - & - & - & - \\
\hline Posaconazole & $0.125-0.5$ & 0.25 & 0.25 & - & - & - & - & 2 & 1 \\
\hline Voriconazole & $0,25-0,5$ & 0.25 & 0.25 & $3(100)$ & - & - & 0 & 3 & 0 \\
\hline Caspofungin & $0,015-0,015$ & 0.015 & 0.015 & - & - & - & - & 3 & 0 \\
\hline \multicolumn{10}{|l|}{ C. dubliniensis $(n=2)$} \\
\hline Amphotericin B & $0.25-0.5$ & - & - & - & - & - & - & - & 2 \\
\hline Ketoconazole & $0.5-1$ & - & - & - & - & - & - & 0 & 2 \\
\hline Fluconazole & $0.5-2$ & - & - & - & - & - & - & 0 & 2 \\
\hline Posaconazole & $0.06-0.5$ & - & - & - & - & - & - & - & - \\
\hline Voriconazole & $0.06-0.125$ & - & - & - & - & - & - & - & - \\
\hline Caspofungin & $0.015-0.015$ & - & - & - & - & - & - & - & - \\
\hline
\end{tabular}




\section{Discussion}

VVC is caused by the pathogenesis of Candida species in the genital tract mucosa and its incidence has increased significantly in recent years (2). The most common Candida species associated with VVC are C. albicans, C. glabrata, C. tropicalis, C. parapsilosis, and C. krusei and Saccharomyces cerevisiae may also cause infection. Most of these mixed infections are due to the association between C. albicans and C. glabrata (2). In the present study, $57 \%$ of $C$. albicans and $26 \%$ of C. glabrata were isolated. These data were found to be consistent with the results of all studies reporting the prevalence of $C$. albicans varying between $33.3 \%$ and $97 \%(22,23)$. Recurrent VVC (RVVC) was encountered in 5\% of cases (5), when C. glabrata was most frequently isolated in 3\% of cases. The second species responsible of RVVC was C. aibicans in $2 \%$ of cases. C. glabrata was the most common type of NAC in the current study. According to most reports, C. glabrata is the most common type of NAC, accounting for half to two-thirds of NAC vaginitis $(24,25)$.

In the present study, the highest rate of VVC was seen in women aged 18-29, a finding consistent with several studies $(23,24,26)$. The underlying mechanism is thought to be through sexual activity and increasing amounts of estrogen produced in this age group, which encourages yeast adhesion and penetration into the vaginal mucosa (8). In multivariate analysis, the first risk factor was that patients with vaginal discharge who were more prone to vaginal candidiasis (adjusted OR: 3.365, 95\% CI: 1.595-7.101). Some authors reported that vaginal discharge is a risk factor in VVC cases $(26,27)$. The second risk factor was vaginal pruritus (adjusted OR: 9.098, 95\% CI: 2.284-36.232), and like with other authors, a correlation was found between VVC and vaginal itching in the present study $(26,28)$. In contrast, some studies have failed to show a link betwe- en VVC formation and vaginal pruritus (29-31). The third risk factor was found to be personal allergic history (adjusted OR: 3.396, 95\% CI: $0.968-11.910$ ). Only $1 \%$ of these patients reported using oral contraceptive pills. However, in the present study, as in many studies, no relationship was found between personal allergic history and VVC (29-31).

In the present study, proteinase activity was found positive in $49(49 \%)$ of 100 Candida strains isolated. Proteinase positivity was observed in $44(77.2 \%)$ of 57 C. albicans strains and 5 (11.6\%) of 43 non-albicans Candida strains. Yamamoto et al. (32) examined 222 Candida strains and found that all 134 C. albicans strains $(100 \%)$ and $24(27.2 \%)$ of 88 non-albicans Candida strains secreted proteinase. Fotedar, AlHedaithy (33) detected proteinase activity in 41 (79\%) of 52 C. albicans strains and 28 (32\%) of 87 non-albicans Candida.

In this study, phospholipase activity was detected in $35(61.4 \%)$ of 57 C. albicans strains and 3 (6.4\%) of 43 non-albicans Candida strains. Fotedar and Al-Hedaithy (33) detected phospholipase activity in all 52 C. albicans strains (100\%), while no phospholipase activity was detected in any of the 42 non-albicans Candida strains. Udayalaxmi and D'Souza (34) found phospholipase activity in $21(52.5 \%)$ of 40 C. albicans strains isolated from genitourinary system samples and 5 (11.9\%) of 42 non-albicans Candida strains. In the present study, 43 (75.4\%) of the C. albicans strains and $22(46.8 \%)$ of the non-albicans Candida strains were found to exhibit beta-hemolytic activity. Luo et al. (16) reported that $C$. albicans strains exhibited beta-hemolysis in hemolytic activity studies. Yenişehirli et al. (17) reported that 147 C. albicans strains isolated from various clinical samples exhibited beta hemolysis.

In the present study, biofilm activity of C. albicans $(82.4 \%)$ strains was higher than non-albicans strains $(68 \%)$. Some studies have reported that $C$. albicans strains have higher biofilm acti- 
vity than non-albicans strains $(16,35)$. However, there are also studies reporting higher biofilm activity of non-albicans Candida strains (36,37). Evaluation of susceptibility to in vitro vaginal Candida isolates is important because of the increased recovery of isolates that show natural or acquired resistance to antifungals. In the present study, microdilution method was used to determine the susceptibility of Candida strains isolated from vaginal samples to amphotericin $\mathrm{B}$, ketoconazole, fluconazole, voriconazole, posaconazole, and caspofungin and MIC values of these antifungals were determined.

In the present study, all Candida strains were determined to be susceptible to amphotericin B. Kalkanci et al. (38) did not detect resistance to amphotericin B in any Candida strain isolated from patients with vaginitis. Gamarra et al. (39) investigated the antifungal susceptibility of yeasts that cause vulvovaginitis, and they found no amphotericin B resistant strains (0.04-0.12 $\mu \mathrm{g}$ / $\mathrm{mL})$.

In the present study, $39(68.4 \%)$ of the C. albicans strains were susceptible to fluconazole, 9 $(15.8 \%)$ were dose-dependent susceptible, and 9 $(15.8 \%)$ were resistant. It was determined that $7(26.9 \%)$ of the C. glabrata strains were resistant, $8(75 \%)$ of the $C$. kefyr and $2(100 \%)$ of the C. dubliniensis strains were not wild type. Seneviratne et al. (37) found fluconazole resistance as $31.7 \%$ in all strains and reported that $40 \%$ of C. albicans were resistant. Different data are available in the literature regarding fluconazole resistance. Some researchers stated that the rate of resistance to this antifungal agent was $46.4 \%$ (40). In another study, it was reported that the species with the highest resistance was $C$. albicans (41). In this study, the mean MIC of Candida species for fluconazole was found between 0.5 and 64 , and resistance was higher in non-albicans species.

In our study, 36 (36\%) of Candida strains for ketoconazole were non-wild type. Chong et al. (42) found that $87.5 \%$ of isolates that cause vaginitis were resistant to ketoconazole. In another study investigating the resistance of three C. albicans, three C. glabrata strains and one Candida spp., it was reported that the susceptibility of these strains to ketoconazole was $96.9 \%$ (43).

In the present study, 43 (75.4\%) of the C. albicans strains were susceptible to voriconazole, $10(17.5 \%)$ were moderately susceptible, and 4 (7.1\%) were resistant. Pesewu et al. (44) reported that $47(71 \%)$ of the $C$. albicans species were resistant to voriconazole. They found $49(83 \%)$ of the C. glabrata and $3(10 \%)$ of the C. krusei and $18(73 \%)$ of the $C$. tropicalis species to be nonwild type $(\mathrm{MIC}>\mathrm{ECV})$. In addition, a moderate sensitivity to $1.1 \%$ voriconazole was determined in $C$. parapsilosis isolates. The rate of resistance to voriconazole was investigated by Fothergill et al. (45) who reported that resistance rates to voriconazole increased in all Candida species compared to previous resistance rates, and this increase was statistically significant, especially in C. glabrata species (previous resistance rate: $6.1 \%$, new resistance rate: $18.4 \%, p<0.0001$ ). In the present study, it was determined that 18 (31.6\%) Candida, 2 (7.7\%) C. kefyr and 6 (50\%) $C$. kefyr strains were not wild type for posaconazole. In one study, all C. albicans, $C$. glabrata and $C$. kefyr strains, $3.5 \%$ of $C$. parapsilosis strains and $1.9 \%$ of $C$. krusei strains were determined as wild type for posaconazole (46). In another study, 11 (32\%) of the C. albicans strains, 5 $(12 \%)$ of the $C$. glabrata strains and $5(10 \%)$ of the $C$. krusei strains were determined to be wild type (47).

In the current study, 54 (94.7\%) of the C. albicans strains were susceptible to caspofungin, 3 (5.3\%) were resistant, 24 (92.3\%) of the C. glabrata strains were susceptible and $2(7 \%, 7)$ were resistant. Etiz et al. (48) found that $16(20 \%)$ of C. albicans, $5(3 \%)$ of C. tropicalis and $8(5 \%)$ of $C$. glabrata strains were resistant to caspofungin among the non-albicans species evaluated. 
Gültekin et al. (14) reported that all 46 Candida spp. strains were susceptible to caspofungin. In a study by Pfaller et al. (49) the rate of resistance to caspofungin was $12.5 \%$ in $C$. krusei.

\section{Limitations of the study}

The most important limiting factor regarding the results obtained is that the data were collected through a tertiary healthcare institution, thus the sampling was small. Therefore, it is not possible to generalize the results of the study to the whole universe. In addition, the composition of Candi$d a$ species that infect women in each geographic region may also vary, as the sociodemographic characteristics of the study area and consequently potential risk factors may differ. Despite these limitations, this study in women of reproductive age in Turkey provide significant information about the patterns and risk factors of VVC infection. According to the results, it was concluded that more studies should be done on $C$. albicans and NAC.

\section{Conclusion}

Considering the ages of the patients in our study, it was observed that VVC affected women of reproductive age more frequently. C. albicans is the most dominant species in patients with VVC, followed by C. glabrata. In the current study, it was found that discharge, burning complaints, and allergies were associated with the development of VVC. In addition to proteinase and phospholipase enzymes, which are considered to be important virulence factors of $C$. albicans, beta-hemolysis and the ability to produce biofilms may also play a role in pathogenesis. In antifungal susceptibility tests, it was determined that there was a little increase in the rate of resistance to fluconazole among Candida strains. Since the epidemiology of vulvovaginal candidiasis changes over time and varies with geographic locations, it is thought that continuous monitoring of changes in the prevalence of Candida species and susceptibility rates is required to guide empirical treatment. Studies on VVC will provide a better understanding of this infection and contribute to the determination of new targets for more effective therapeutic approaches to Candi$d a$ strains that are the causative agents of VVC.

\section{Authors' contribution}

S.T. (Conceptualization; Data curation; Formal analysis; Investigation; Methodology; Resources; Software; Supervision; Validation; Visualization; Writing - original draft; Writing -review \& editing);

I.H.K (Supervision; Validation; Visualization; Writing - original draft; Writing -review \& editing);

J.E.H. (Formal analysis; Investigation; Methodology; Resources; Software; Supervision; Validation; Visualization);

E.G.M. (Conceptualization; Data curation; Formal analysis; Investigation);

F.E.T. (Data curation; Formal analysis; Investigation; Methodology; Resources);

I.D.K. (Supervision; Validation; Visualization; Writing - original draft; Writing -review \& editing)

\section{Conflict of interests}

None to declare.

\section{Acknowledgments}

The authors would like to thank to Scientific Research Council of Gaziantep University, for the financial support (Project No: FEF.DT.19.16).

\section{References}

1. Balcı O, Çapar M. Vaginal enfeksiyonlar. Turk J Obstet Gynecol Der Derg 2005;2(5):14-20.

2. Gonçalves B, Ferreira C, Alves CT, Henriques M, Azeredo J, Silva S. Vulvovaginal candidiasis: Epidemiology, microbiology and risk factors. Crit Rev Microbiol 2016 
;42(6):905-27. DOI: 10.3109/1040841X.2015.1091805

3. Bostănaru A, Roșca I, Minea B, Năstasă V, Foia L, Marincu I, et al. Genotype comparison of Candida albicans isolates from different clinical samples. Revista Romana de Medicina de Laborator 2019; 27( 3). 32732. DOI: 10.2478/rrlm-2019-0027

4. Beigi RH, Meyn LA, Moore DM, Krohn MA, Hillier SL. Vaginal yeast colonization in nonpregnant women: a longitudinal study. Obstet Gynecol 2004;104(5):92630. DOI: 10.1097/01.AOG.0000140687.51048.73

5. Rodrigues CF, Silva S, Henriques M. Candida glabrata: a review of its features and resistance. Eur J Clin Microbiol Infect Dis 2014;33(5):673-88. DOI: 10.1007/ s10096-013-2009-3

6. Naglik JR, Challacombe SJ, Hube B. Candida albicans secreted aspartyl proteinases in virulence and pathogenesis. Microbiol Mol Biol Rev 2003;67(3):400-28. DOI: 10.1128/MMBR.67.3.400-428.2003

7. Nagashima M, Yamagishi Y, Mikamo H. Antifungal susceptibilities of Candida species isolated from the patients with vaginal candidiasis. J Infect Chemother 2016;22(2):124-6. DOI: 10.1016/j.jiac.2015.08.008

8. Sobel JD. Vulvovaginal candidosis. Lancet 2007;369(9577):1961-71. DOI: 10.1016/S01406736(07)60917-9

9. Apalata T, Longo-Mbenza B, Sturm A, Carr W, Moodley P. Factors associated with symptomatic vulvovaginal candidiasis: a study among women attending a primary healthcare clinic in Kwazulu-Natal, South Africa. Ann Med Health Sci Res 2014;4(3):410-6. DOI: 10.4103/2141-9248.133470

10. Amouri I, Sellami H, Borji N, Abbes S, Sellami A, Cheikhrouhou F, et al. Epidemiological survey of vulvovaginal candidosis in Sfax, Tunisia. Mycoses 2011;54(5):e499-e505. DOI: 10.1111/j.14390507.2010.01965.x

11. Romeo O, Criseo G. Candida africana and its closest relatives. Mycoses 2011;54:475-86. DOI: 10.1111/j.14390507.2010.01939.x

12. Marot-Leblond A, Nail-Billaud S, Pilon F, Beucher B, Poulain D, Robert R. Efficient diagnosis of vulvovaginal candidiasis by use of a new rapid immunochromatography test. J Clin Microbiol 2009;47(12):3821-5. DOI: 10.1128/JCM.01168-09

13. Staib F. Serum-proteins as nitrogen source for yeastlike fungi. J Med Vet Mycol 1966;4(3):187-93. DOI: $10.1080 / 00362176685190421$

14. Gültekin B, Eyigör M, Tiryaki Y, Kırdar S, Aydın N. Kan kültürlerinden izole edilen Candida sușlarında antifungal duyarlılığın ve bazı virülans faktörlerinin araştırılması ve RAPD-PCR ile genotiplendirilmesi. Mikrobiyol Bul 2011;45(2):306-17.

15. Price MF, Wilkinson ID, Gentry LO. Plate method for detection of phospholipase activity in Candida albicans. J Med Vet Mycol 1982;20(1):7-14. DOI:
$10.1080 / 00362178285380031$

16. Yenişehirli G, Bulut Y, Tuncoglu E. Phospholipase, proteinase and hemolytic activities of Candida albicans isolates obtained from clinical specimens. Mikrobiyol Bul 2010;44(1):71-7.

17. Luo G, Samaranayake LP, Yau JY. Candida species exhibit differential in vitro hemolytic activities. J Clin Microbiol 2001;39(8):2971-4. DOI: 10.1128/ JCM.39.8.2971-2974.2001

18. Branchini M, Pfaller M, Rhine-Chalberg J, Frempong $\mathrm{T}$, Isenberg H. Genotypic variation and slime production among blood and catheter isolates of Candida parapsilosis. J Clin Microbiol 1994;32(2):452-6. DOI: 10.1128/JCM.32.2.452-456.1994

19. Wayne P. Reference method for brothdilution anti-fungal susceptibility testing of yeasts. 3rd ed. Wayne: Clinical and Laboratory Standards Institute; (Approved standard. M27-S3). Allured Publishing Corporation: Carol Stream, IL, USA; 2008.

20. Wayne P. Reference method for broth dilution anti $\neg$ fungal susceptibility testing of yeasts; fourth informational supplement. Wayne: Clinical and Laboratory Standards Institute; (Document M27-S4). Allured Publishing Corporation: Carol Stream, IL, USA; 2012.

21. Pfaller M, Espinel-Ingroff A, Boyken L, Hollis R, Kroeger J, Messer S, et al. Comparison of the broth microdilution (BMD) method of the European Committee on Antimicrobial Susceptibility Testing with the 24-hour CLSI BMD method for testing susceptibility of Candida species to fluconazole, posaconazole, and voriconazole by use of epidemiological cutoff values. J Clin Microbiol 2011;49(3):845-50. DOI: 10.1128/ JCM.02441-10

22. Alfouzan W, Dhar R, Ashkanani H, Gupta M, Rachel C, Khan ZU. Species spectrum and antifungal susceptibility profile of vaginal isolates of Candida in Kuwait. J Mycol Med 2015;25(1):23-8 DOI: 10.1016/j.mycmed.2014.10.021

23. Mtibaa L, Fakhfakh N, Kallel A, Belhadj S, Salah NB, Bada N, et al. Vulvovaginal candidiasis: Etiology, symptomatology and risk factors. J Mycol Med 2017;27(2):153-8. DOI: 10.1016/j.mycmed.2017.01.003

24. Maraki S, Mavromanolaki VE, Stafylaki D, Nioti E, Hamilos G, Kasimati A. Epidemiology and antifungal susceptibility patterns of Candida isolates from Greek women with vulvovaginal candidiasis. Mycoses 2019;62(8):692-7. DOI: 10.1111/myc.12946

25. Makanjuola O, Bongomin F, Fayemiwo SA. An update on the roles of non-albicans Candida species in vulvovaginitis. JFOUCU 2018;4(4):121. DOI: 10.3390/ jof4040121

26. Siddiqui R. Clinical patterns and risk factors of vulvo-vaginal candidiasis among women of reproductive age attending a tertiary hospital in central India. Stam- 
ford J Microbiol 2019;9(1):27-31. DOI: 10.3329/sjm. v9i1.45655

27. Narayankhedkar A, Hodiwala A, Mane A. Clinicoetiological characterization of infectious vaginitis amongst women of reproductive age group from Navi Mumbai, India. J Sex Transm Dis 2015;2015:817092. DOI: $10.1155 / 2015 / 817092$

28. Altayyar IA, Alsanosi AS, Osman NA. Prevalence of vaginal candidiasis among pregnant women attending different gynecological clinic at South Libya. Eur J Exp Biol 2016;6(3):25-9.

29. Guzel AB, Ilkit M, Akar T, Burgut R, Demir SC. Evaluation of risk factors in patients with vulvovaginal candidiasis and the value of chromID Candida agar versus CHROMagar Candida for recovery and presumptive identification of vaginal yeast species. Med Mycol 2011;49(1):16-25. DOI: 10.3109/13693786.2010.497972

30. Guzel AB, Ilkit M, Burgut R, Urunsak IF, Ozgunen FT. An evaluation of risk factors in pregnant women with Candida vaginitis and the diagnostic value of simultaneous vaginal and rectal sampling. Mycopathologia 2011;172(1):25-36. DOI: 10.1007/s11046-011-9392-z

31. Güzel AB, Aydın M, Meral M, Kalkancı A, Ilkit M. Clinical characteristics of Turkish women with Candida krusei vaginitis and antifungal susceptibility of the C. krusei isolates. Infect Dis Obstet Gynecol 2013;2013:698736. DOI: 10.1155/2013/698736

32. Yamamoto T, Nohara K, Uchida K, Yamaguchi H. Purification and characterization of secretory proteinase of Candida albicans. Microbiol Immunol 1992;36(6):63741. DOI: $10.1111 / j .1348-0421.1992 . t b 02064 . x$

33. Fotedar R, Al-Hedaithy S. Comparison of phospholipase and proteinase activity in Candida albicans and C. dubliniensis. Mycoses 2005;48(1):62-7. DOI: 10.1111/j.1439-0507.2004.01057.x

34. Udayalaxmi SJ, D'Souza D. Comparison between virulence factors of Candida albicans and non-albicans species of Candida isolated from genitourinary tract. J Clin Diagn Res 2014;8(11):15-7.

35. Morschhäuser J. Regulation of white-opaque switching in Candida albicans. Med Microbiol Immunol 2010;199(3):165-72. DOI: 10.1007/s00430-010-01470

36. Dabiri S, Shams-Ghahfarokhi M, Razzaghi-Abyaneh M. Comparative analysis of proteinase, phospholipase, hydrophobicity and biofilm forming ability in Candida species isolated from clinical specimens. J Mycol Med 2018;28(3):437-42. DOI: 10.1016/j.mycmed.2018.04.009

37. Seneviratne CJ, Rajan S, Wong SS, Tsang DN, Lai CK, Samaranayake LP, et al. Antifungal susceptibility in serum and virulence determinants of Candida bloodstream isolates from Hong Kong. Front Microbiol 2016;7:216. DOI: 10.3389/fmicb.2016.00216
38. Kalkanci A, Güzel A, Jabban I, Aydin M, Ilkit M, Kuştimur S. Candida vaginitis in non-pregnant patients: a study of antifungal susceptibility testing and virulence factors. J Obstet Gynaecol 2013;33(4):37883. DOI: $10.3109 / 01443615.2013 .767323$

39. Gamarra S, Morano S, Dudiuk C, Mancilla E, Nardin ME, de los Angeles Méndez E, et al. Epidemiology and antifungal susceptibilities of yeasts causing vulvovaginitis in a teaching hospital. Mycopathologia 2014;178(3-4):251-8. DOI: 10.1007/s11046-014-97802

40. Subramanya SH, Baral BP, Sharan NK, Nayak N, Metok Y, Sathian B, et al. Antifungal susceptibility and phenotypic virulence markers of Candida species isolated from Nepal. BMC Res Notes 2017;10(1):543. DOI: $10.1186 / \mathrm{s} 13104-017-2852-\mathrm{x}$

41. Morris AJ, Rogers K, McKinney WP, Roberts SA, Freeman JT. Antifungal susceptibility testing results of New Zealand yeast isolates, 2001-2015: Impact of recent CLSI breakpoints and epidemiological cut-off values for Candida and other yeast species. J Glob Antimicrob Resist 2018;14:72-7. DOI: 10.1016/j.jgar.2018.02.014

42. Chong PP, Hadi SRA, Lee YL, Phan CL, Tan BC, Ng $\mathrm{KP}$, et al. Genotyping and drug resistance profile of Candida spp. in recurrent and one-off vaginitis, and high association of non-albicans species with non-pregnant status. Infect Genet Evol 2007;7(4):449-56. DOI: 10.1016/j.meegid.2007.01.004

43. Donders GG, Mertens I, Bellen G, Pelckmans S. Self-elimination of risk factors for recurrent vaginal candidosis. Mycoses. 54(1):39-45. DOI: 10.1111/j.14390507.2009.01754.x

44. Pesewu GA, Feglo PK, Boateng RK, Fayemiwo SA. Prevalence and Antifungal Susceptibility Pattern of Candida Isolates from Women with Recurrent Vulvovaginal Candidiasis in Ghana - A Review of Laboratory Reports. Research Square; 2020. DOI: 10.21203/ rs.3.rs-33278/v1

45. Fothergill AW, Sutton DA, McCarthy DI, Wiederhold NP. Impact of new antifungal breakpoints on antifungal resistance in Candida species. J Clin Microbiol 2014;52(3):994-7. DOI: 10.1128/JCM.03044-13

46. Arikan-Akdagli S, Gülmez D, Doğan Ö, Çerikçioğlu N, Dereli MD, Birinci A, et al. First multicentre report of in vitro resistance rates in candidaemia isolates in Turkey. J Glob Antimicrob Resist 2019;18:230-4. DOI: 10.1016/j.jgar.2019.04.003

47. Mahmoudabadi AZ, Rezaei-Matehkolaei A, Ghanavati F. The susceptibility patterns of Candida species isolated from urine samples to posaconazole and caspofungin. Jundishapur J Microbiol 2015;8(3):e24298. DOI: $10.5812 / \mathrm{jjm} .24298$

48. Etiz P, Kibar F, Ekenoğlu Y, Yaman A. Kan kültürlerinden izole edilen Candida türlerinin dağılımının ve antifungal duyarlıl1klarının retrospektif olarak değerlendir- 
ilmesi. Ankem Derg 2015;29(3):105-13.

49. Pfaller MA, Castanheira M, Messer SA, Moet GJ, Jones RN. Echinocandin and triazole antifungal susceptibility profiles for Candida spp., Cryptococcus neoformans, and Aspergillus fumigatus: application of new CLSI clinical breakpoints and epidemiologic cutoff values to characterize resistance in the SENTRY Antimicrobial Surveillance Program (2009). Diagn Microbiol Infect Dis 2011;69(1):45-50. DOI: $10.1016 / j$.diagmicrobio. 2010.08 .013 